\title{
NOTES FROM THE PLYMOUTH AQUARIUM. II
}

\author{
By Douglas P. Wilson, D.Sc. \\ The Plymouth Laboratory
}

\begin{tabular}{|c|c|c|c|c|c|c|}
\hline \multicolumn{7}{|c|}{ CONTENTS } \\
\hline & & & & & & PAGE \\
\hline An alga disliked by $M$ ugil chelo & Cuvier & . & 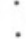 & & & 203 \\
\hline Behaviour of Gadus morrhua L. & . & . & $\theta^{\circ}$ & & $\sigma^{\circ}$ & 203 \\
\hline Cepola rubescens L. in captivity & . & . & . & & & 204 \\
\hline Polyprion americanum (Schneider & in $\mathrm{ca}$ & & & . & . & 207 \\
\hline
\end{tabular}

The purpose of these occasional notes has already been explained (Wilson, I949). The present notes comprise a number of observations on the habits of fishes.

\section{The FEeding of TORPEDO NOBILIANA Bonaparte}

As known from ancient times, Electric Rays (Torpedo) have the power of giving severe numbing shocks, and it has repeatedly been stated that this power, which is electrical, is used both as a means of protection and for paralysing prey. That the shock is used in the capture of prey seems never to have been definitely proved. Indeed Roule (1935, p. I6I) expresses the opinion that the electric shock is not used for securing food and even doubts that it is normally and effectively used as a means of defence. There appears to be no detailed account of the manner in which Torpedo feeds, but the ninth edition (1925) of the Guide to the Aquarium of the Zoological Station at Naples mentions (p. I06) that the Electric Ray rises from the mud to throw itself against approaching mullet (Mugil), and that the mullet, overcome by fright and electric shock, fall to the ground to be eaten. This very short and incomplete account was not seen until after the following paragraphs had been written.

Both Torpedo nobiliana Bonaparte and $T$. torpedo $\mathrm{L}$. occur from time to time off Plymouth, the former being by far the commoner, and both have been kept in our aquarium tanks. They are sluggish fishes, spending most of the time lying still on the bottom, occasionally swimming for short spells. They swim by sculling with the tail, which has a large caudal and two dorsal fins. This mode of swimming differs strikingly from that of normal rays, which undulate the pectoral fins and trail their tails; it resembles the swimming movements of Rhina squatina (L.), another fish with a sluggish disposition and, as noted below, some other resemblances to Torpedo.

In the I930's some time was spent observing Torpedo in the hope of discovering the manner in which the prey is captured. The rays observed never attempted to secure squid or dead fish thrown into the tank; but round fishes, 
such as cod (Gadus morrhua L.) and pollack (G. pollachius L.), if kept in the same tank, gradually disappeared one by one. In March 1935 a Torpedo nobiliana, $2 \frac{1}{2}$ to $3 \mathrm{ft}$. long, was seen with the tail of a cod, about $20 \mathrm{in}$. long, sticking out of its mouth. The cod was really too big for the ray and took over an hour to disappear. For several days afterwards the ray had a bloated appearance. Later in the same year I arrived at the tank in time to see a pollack disappearing into the mouth of the same or a similar ray. Late in 1937 another $T$. nobiliana almost certainly killed a pollack much too big for it to swallow. The pollack was found lying on the bottom of the tank still twitching. Round its middle was a dark mark, and dissection revealed that the vertebral column was broken. However, in spite of much time spent in observation, the manner of attack was never seen.

When the aquarium was reopened after the war further specimens of Torpedo were obtained, but in general they were unwelcome owing to the apparent impossibility of feeding them except with living fish. The same difficulty had occurred with Rhina squatina, but had been overcome by drawing dead fish through the water on the end of a wire. When the fish arrived near its mouth, the Rhina gave a very quick upward thrust of the head and rose from the ground to seize it. In Rhina the large mouth is at the extreme anterior end and is well suited to this habit. It was thought that Torpedo might similarly react to a dead fish drawn smartly through the water to within striking distance, though how it would attack it was a matter for speculation. The mouth of Torpedo is relatively much smaller than that of Rhina and is situated underneath the head well behind the anterior end, a poor position, apparently, for seizing actively swimming prey.

In the autumn of 1952, when two medium-sized Torpedo nobiliana (each about $2 \mathrm{ft}$. long, one a male, the other a female) had settled down in the largest tank, the feeding technique used for Rhina was tried and at once proved successful. A dead pout, Gadus luscus L., on the end of a wire fixed to a bamboo pole, was pounced upon by the male ray as soon as it was drawn to a position a few inches above the bottom in front of the ray. With a very quick movement the ray sprang forwards and upwards and made to envelop the fish, its wings (pectoral fins) and snout (the straight anterior border of the head) being curled around ventrally. The stiff wire prevented the completion of the manoeuvre, and as the pout was pulled away and upwards the ray adopted first a vertical position, with the wings surrounding the prey, and finally turned over upside-down in mid-water. It could then be seen that the pout was between the jaws of the ray, whose wings, snout, pelvics and tail were all bent or bunched upwards (that is ventrally) as if to surround it. The pout was unhooked from the wire, and the ray righted itself and flattened itself out on the bottom, by which time the meal had been swallowed. Much the same performance was repeated with another pout, after which the ray lost interest and on that day gave no further display. 
The female was then tempted. It pounced in a similar manner, but, encountering obstructing rockwork, failed to secure the fish. In spite of repeated tempting no further interest in trailed fish was shown that day.

Subsequently many more pouncing responses were elicited and the manner in which Torpedo normally captures its prey became clear. The ray lies perfectly still on the bottom until a fish swims within reach, that is into a position just in front of the ray and not too far above the bottom. For a ray $2 \mathrm{ft}$. long the maximum distance above bottom seems to be about $6 \mathrm{in}$. The fish can approach from any direction. On one occasion a ray pounced on a bamboo pole as it was pushed quickly downwards to retrieve a detached bait lying motionless on the bottom. The bait must not be moved too slowly, otherwise a response does not seem to be forthcoming. The experience with the bamboo pole suggests, too, that detailed shape is unimportant. The bait need not touch the ray. Baits used were pout, hake and horse mackerel. The baits were attached directly to a wire, or to a nylon thread attached to the end of the wire. Baits on nylon threads were completely covered over and pinned to the bottom by the pouncing ray, the wings and anterior border of the head being bent downwards to entrap it. This pinning of the prey to the bottom is a normal procedure for ordinary rays; those which feed on crustaceans such as small crabs swim over them and pin them down until the jaws are able to take hold. Chewing movements are then visible on the upper surface above the gill arch region, and such chewing movements were sometimes seen when Torpedo had a fish below it. Strangely enough, Torpedo never succeeded in taking hold of a dead fish lying motionless under it, however long it was left there, and the fish was invariably easily pulled out from under the ray. The only fish which were secured and eaten were on wires. A possible explanation is that the Torpedo missed the struggles or other movements of living prey, and that the slight prodding which must occur with a dead fish on a stiff wire held in the hand simulated those movements and enabled the ray to find it by the feel. Even so, although the rays readily pounced, sometimes repeatedly, on a fish trailed on a wire it was not often that they succeeded in getting it into the mouth and eating it.

The feeding reactions of Torpedo, so far as they appear to the eye, are not very different from those of ordinary rays in the Plymouth tanks, except that they are quicker and appear to depend less on the olfactory sense. Large Raia clavata are known to feed on fish such as herrings and sprats (Steven, I947), but on the whole the food of ordinary rays consists of crustaceans, smaller and less able to escape quickly. Torpedo catches relatively large active fishes, and it seems a reasonable conclusion that it is able to do so because it can numb and quieten them with its electric organs. But before this conclusion can be accepted the giving of the shock during capture needs to be demonstrated.

A dead horse mackerel, Caranx trachurus (L.), about 9 in. long, was fixed to the end of a waterproof electric flex. Each wire of the double flex was 
soldered to an electrode and the electrodes were inserted into the muscular tissues of the fish, one at each end. The flex was connected to a Pye Scalamp Galvanometer. The fish was now trailed in the usual way. Several times the fish touched the back of the ray but no deflexion of the galvanometer occurred. Eventually the ray (the female) pounced, and at that instant when it folded its wings and head on to the prey a strong shock was registered. The ray failed to secure the fish. After several more attempts without any response the female was abandoned and the male was tried. As soon as the bait arrived in the proper position the ray pounced and again a strong shock was registered. This time the bait was secured and the ray began to swallow it with the flex still firmly attached. To release the flex by pulling out the electrodes the ray had to be drawn vertically up in the water and almost over on to its back, and up towards the surface, its wings and snout being folded ventrally as usual. It was some little time before the electrodes were tugged away, just as the tail of the horse mackerel was disappearing into the mouth of the ray, but no further shock was registered. The shocks given by both rays were probably considerable. The galvanometer, on lowest sensitivity, gave far more than fullscale deflexion, indicating that the shock was of the order of volts. With the instrument used it was not possible to obtain a better measurement; the purpose had been only to demonstrate that a shock is given at the moment the ray touches its prey.

The effect on a living fish may perhaps be surmised from an occasion when a turbot attempted to seize the bait at the moment the Torpedo pounced. The Torpedo missed the bait and partially enveloped the turbot in a vigorous manner, pinning it to the ground. Convulsive contractions of the electricorgan region (these are mentioned by Day, I880-84) and strong chewing movements were seen. The tail of the turbot projected from under the ray at one side and curled stiffly upwards, and was not flapping about as might be expected of a trapped but otherwise unharmed turbot. After a time the chewing motions ceased but the ray still lay over the turbot. Eventually the ray was pushed aside with a pole, revealing the turbot, its tail now back on the ground, alive and undamaged but breathing perhaps a little slowly. After a few minutes it swam away, and it is still alive. The Torpedo gave no further responses that day. It is well known that after use the power of the electric organs is weakened and time is needed for recuperation.

During these observations the use by Torpedo of its electric powers in a defensive manner was also seen. On several occasions a dogfish or nursehound nosing over the ground for food came into contact with a Torpedo and on doing so gave a sudden start and swam away. Contractions of the electricorgan region were not then specially noticed. Conger eels nosing a ray have suddenly come to an abrupt stop and then quickly retreated backwards a long way. On two separate occasions large lobsters walking over the ray towards a piece of food suddenly jumped backwards with a vigorous flap of the tail. 
At other times lobsters have walked unharmed over the rays. Once a Torpedo and a large Rhina lay facing one another a short distance apart. On a fish being trailed between them both attempted to seize it at the same instant, with the result that they collided head-on in mid-water. At that moment the Rhina gave a sudden start and swam away, displaying unusual energy for its species. To the onlookers there was no doubt that it had received a shock, probably the one intended for the prey.

The observations recorded throw little or no light on the manner in which the prey is perceived. The eyes of Torpedo, like those of Rhina, are small, but they may be sufficiently sensitive to detect the movement of an object of approximately the size and shape of a swimming fish suitable for food, and to fix its position. In nature all such objects are likely to be suitable for food and not a source of danger. Bateson (I890) figures the eyes of both Torpedo and Rhina and shows that while by day their pupils are only narrow slits, by night they are circular and widely open. However, the prey may be perceived by other senses, by the disturbance it makes in the water, or in other ways. The point demands investigation.

In these observations I have been much assisted by Mr G. R. Forster, and by the attendants Messrs W. H. Gladwell and A. N. Bennett. I am indebted to $\mathrm{Mr}$ B. C. Abbott for lending the galvanometer, and Messrs F. J. Warren and A. E. Stoate for working it.

\section{An Alga Disliked by Mugil chelo Cuvier}

In a tank containing grey mullet (Mugil chelo Cuvier) any algal growth on sides and rock is usually kept very short by their browsing activities. Consequently, when in I950 an isolated growth of a small red seaweed on the top of a rock arch stood out conspicuously amid the eaten-down growths all around, the event was specially noted. Soon patches appeared in other parts of the tank and were obviously being left alone by the mullet. In April I95I the alga covered fair areas of rockwork and of the sides of the tank and overflow pipe. In the same month the alga was identified by $\operatorname{Dr} M$. W. Parke as Polysiphonia urceolata (Dillw.) Grev. in fruiting condition bearing tetrasporangia. A year later this small red seaweed covered almost the whole of the rockwork, and most of the sides of the tank and the overflow pipe. Several samples were taken and the previous identification checked. On this occasion the plants had vorticellids and other organisms growing on them, but the main bulk of the samples consisted of Polysiphonia urceolata, which can therefore be retarded as being distasteful to grey mullet.

\section{BEHAVIOUR OF GADUS MORRHUA L.}

In December 1947 several evenings were spent photographing three large cod (Gadus morrhua L.) in the second-biggest tank in the aquarium $\left(15 \frac{3}{4} \times 9 \times 4 \frac{1}{4} \mathrm{ft}\right.$. deep). One of the cod was blind in the right eye and it 
invariably took up a position in the top left-hand corner of the tank with its blind side close to the glass; from this position the good eye could survey the whole interior of the tank. The other two fish generally swam about together, keeping mainly to the other half of the tank. If together or singly they reached its neighbourhood, the blind-eyed fish immediately rushed at them and chased them away, returning to its corner afterwards. This blind-eyed cod died in March 1949 and proved to be female with maturing but not ripe ovaries. It was $7 \mathrm{I} \mathrm{cm}$. long.

The two companionable cod rarely separated for long and one would frequently rub its side against the other, often retiring a short distance to swim quickly back again and, swerving laterally, graze the lower middle region of its body against the other fish as it rushed past. The behaviour of these two strongly suggested courtship. It was always the same fish which followed the other about and took the active part in these proceedings. This fish died in October 1949; it was a male, $72 \mathrm{~cm}$. long, with, at the time of death, immature testes. Its companion, which was so attractive to it, expired some weeks after the evening observations here recorded. It had very swollen ovaries and may have died from egg-binding. The length was not recorded but was close to that of the male.

Attempts to photograph the courtship were unsuccessful. The actions took place quickly at intervals, always well back in the tank almost out of range of the flashlights.

\section{CEPOLA RUBESCENS L. IN CAPTIVITY}

Day (1880-84) and Fage (1918) express the opinion that Cepola rubescens L., commonly called the Red Bandfish, prefers rocky situations - at moderate depths, but at Plymouth this is not so. Cepola is most frequently taken in the trawl on, or near, the Rame Mud, a few miles seawards from Rame Head, at depths round about 25 fathoms, and it is rarely taken on other grounds. Specimens rarely survive capture; distension of the air-bladder caused the fishes to float at the surface when placed in a tank and death usually followed within a few hours. Since November 1950, however, a few individuals, taken in trawl hauls of short duration and raised more slowly than usual to the sea surface, have survived. A few have lived for some months in the aquarium, though not all together at the same time. The first of these, a Cepola $43 \mathrm{~cm}$. long, was brought in on 23 November 1950 and lived until 26 June I95I, when it was attacked and partly swallowed by a very hungry three-bearded rockling (Onos tricirratus (Bloch)), which had been living in the same tank for the whole of that period. Other specimens did not survive so long, dying from various causes. One or two kept for 9 or Io weeks were never seen to feed. Another fish got itself jammed between the edge of the glass and the wall of the tank; another was killed by a lemon dab (Pleuronectes microcephalus Donovan) which pinned it down, perhaps accidentally, under its body; some 
died without obvious cause. Those which survived for more than a few days were a small proportion of those brought in alive. The species thus seems to be readily injured, both in the trawl and in simple accidents during captivity.

In captivity a red bandfish usually takes some time to learn to feed. At first it may catch a few Hemimysis lamornae (Crouch), which breed in the tanks, but sooner or later it generally learns to take small pieces of squid (Loligo) or worms (Nereis) sinking down towards it from above, though for many days it may 'blow' such pieces out of its way. Once it is feeding it will compete for food with other fishes, and some individuals have even learnt to take squid from the hand. Towards other fishes Cepola can be fierce, biting viciously with long sharp teeth at small pollack and soles. A large Cepola was seen to snap at a smaller one.

Cepola swims slowly, with very pronounced body waves. The tank in which the specimens were kept was probably too small to encourage speedy swimming, but forward darts after food, followed by rapid backward retreats, were often seen at feeding time. While a few individuals have swum, or rested, horizontally close to the bottom the majority have maintained themselves vertically head uppermost, swimming with slow body waves, with the ventral surface close up against the slate sides or back of the tank, but never against the glass. This position may have been adopted to avoid the soles living on the bottom in the same tank; but it seems more probable that the vertical posture is normal. However, the individuals which by day always adopted such a position were occasionally seen, especially at night, after sudden switching on of the light, to be swimming slowly over, or resting horizontally on, the bottom. A variation in posture sometimes adopted for short periods has been to curl the posterior third, or half, of the body into a loop, and to rest with the loop on the ground, the anterior part of the body being upright. Sometimes a length of tail has been laid on its side flat along the ground with the rest of the body raised up off the bottom at an angle of about $30^{\circ}$, but bent or twisted to bring the front portion and head into the normal dorsum-upper-most position.

The vertical swimming habit in such an elongated tapering fish suggested to $\mathrm{Mr}$ P. G. Corbin that the fish may normally inhabit a vertical burrow, either of its own construction or one occupied, or abandoned, by some burrowing animal such as Upogebia, which is numerous where Cepola commonly occurs. Indeed, $\mathrm{Mr}$ Corbin informs me that more than once a Cepola has been brought up in a dredge full of mud and burrowing bottom fauna. With this possibility in mind vulcanite pipes of various diameters and lengths were put into the tank, horizontally, vertically and at various angles, to see if the Cepola would enter them, but none did so. ${ }^{1}$

1 On 24 February 1953, while this paper was in proof, a Cepola, length about 20 in., was obtained in unusually good condition. It swam vertically, as usual, and four days later was found to be inside a long vulcanite pipe of about $3 \frac{1}{2}$ in. internal diameter. This pipe (which was suspended vertically with its lower end just above the tank floor in one corner, its upper end above water level) was receiving water from an inflow nozzle. 
The surmise that Cepola normally lives in a burrow received support when one was several times seen, in July I95I, to take up a mouthful of the shell gravel covering the floor of its tank and blow it out again. Later, in February I952, another specimen made determined efforts to excavate a hole and it got as far as making a well-defined depression in the gravel. Had the gravel been deeper, and had the sides of the hole not slid in as the bottom was excavated, the hole would undoubtedly have been dug out to a fair depth. Twenty or thirty times, after this fish was first observed to be busy, a mouthful of gravel was removed from the hole and deposited well to one side. On each occasion the Cepola approached the hole swimming horizontally over the ground, bent down its head vertically into the hole, seized a mouthful of gravel, straightened up and swam a short distance to where the gravel was dropped out of its mouth, and returned for another load. Now and again it rested upright on coiled tail, the loop of the tail within the shallow depression which was the hole it had made. In a stiff mud, such as that of the region where most Cepola are caught, the actions just described would excavate a vertical burrow which if carried deep enough would accommodate the fish. If it does live in such a burrow it may have its head near the entrance ready to dart out at passing prey. The fact that specimens which swam vertically by day were sometimes seen in a horizontal position at night may indicate that during the hours of darkness they naturally come out of their burrows to feed. Those that are caught in the trawl by day may also be out hunting for food. However, it is not yet established that Cepola ever lives in a burrow, and further observations are needed to confirm or refute this idea. Another possibility is that the excavating activity is connected with nest-building, but this seems unlikely, as the available evidence, although incomplete, indicates that the egg is pelagic (Holt, I89I). Moreover, Clark (I920) states that the spawning period is in August, whereas the most intense excavating activity was observed in February.

Since the above account was written further observations have been made. On 7 January 1953 several young Cepola, 5-10 cm. long, were caught in an Agassiz trawl $6 \frac{1}{2}$ miles south of the Breakwater, on a bottom of slightly muddy sand. When brought in they were floating with distended air-bladders, but the most lively of them were placed in one of the central table tanks in the aquarium and by the next morning a few of these were swimming normally. About noon Mr P. G. Corbin called my attention to one which was burrowing in sand beside a perforated vulcanite partition whose lower edge rested on the sand. The burrow was being constructed partially under this partition, the fish picking up in its mouth sand from the bottom of its hole, turning round and blowing it away well to one side. Relative to the size of the fish the depth of sand was sufficient for the excavation of a hole, as wide as it was deep, into which the fish was able to retire with its tail coiled around inside and its head out of the entrance. In a corner of the tank another small Cepola had 
excavated a shallower depression, but it and several others were swimming vertically in the corners or against the slate sides of the tank. Throughout the day they so continued, and the fish in its hole remained there. The following morning the latter and all but two of the others were missing. A search discovered a small Cottus bubalis Euphrasén hiding under a rock. When killed and opened the partially digested remains of at least two Cepola were found in its stomach.

The burrowing of these very young Cepola disposes of the idea that only breeding individuals do so, in order to make nests, and short of final proof strongly supports the supposition that Cepola normally lives in a hole or a burrow which it makes for itself. The form of the burrow has still to be determined, whether long and deep to take a fish stretched at full length, or shallow and wide in which it could lie coiled up. Perhaps both types are made, according to the depth and consistency of the bottom deposit. It may be that they are often excavated to pass beneath a stone or other solid object lying on or embedded in the surface of the deposit, in a similar way to the hole made under the partition.

\section{POLYPRION AMERICANUM (SCHNEIDER) IN CAPTIVITY}

A fine Wreck-fish or Stone-bass, Polyprion americanum (Schneider), about $50 \mathrm{~cm}$. long, was caught, on 7 September I95I, about 5 miles south-west of Bolt Tail by Mr F. Jarvis, Hope Cove, Kingsbridge, and brought to the Laboratory, where it was placed in a tank containing various species of Labridae. The fish had been found inside a tea-chest which was floating on its side; there were no barnacles or other obvious growths on the tea-chest, according to information obtained from Mr Jarvis. Couch (I862) states that the species is especially prone to gather under masses of floating wreckage where it feeds on smaller fishes attracted to the shelter of suspended barnacles or weeds.

This specimen, probably the first of its species to be kept alive at Plymouth, soon settled down and since its arrival has grown about $5 \mathrm{~cm}$. It has fed mainly on fresh fish, readily taking whole pout, Gadus luscus L., and small whiting, Gadus merlangus L. It will not eat squid-which most of the other fishes take so eagerly-unless it is very hungry. It has a fierce disposition which it wreaks principally on the largest ballan wrasses (Labrus bergylta Ascanius), leaving alone the smaller species, the gaudily coloured Cuckoo Wrasses (Labrus mixtus Kröyer), and even the smaller ballans. Almost whenever the large ballan wrasses, 30-40 cm. long, appear out of hiding amid the rocks, they are chased and often bitten. In August I952, $\mathrm{Mr}$ W. H. Gladwell, the aquarium attendant, saw the Polyprion kill a large ballan wrasse by repeatedly pushing or beating it against the slate wall of the tank, the wrasse being held by the back. These large wrasses are too big to be 
eaten; and the Polyprion is scarcely likely to attack them because it is hungry, for it could more easily catch and eat the smaller wrasses. Indeed, the Polyprion attacks the large fishes as readily after a full meal as before. It is apparently the sight of another large fish which arouses the animosity of the Polyprion, which may well have a habit of attacking other fish near its own size, or larger, which appear to be encroaching on its territory. As a fisheater it would tolerate the presence of fishes of a size suitable for food.

When not attacking another fish the Polyprion swims slowly up and down its tank in mid-water and does not frequent the rocks as do the wrasses. Forward propulsion is aided by movements of the enlarged lobes of posterior dorsal and anal fins; the spiny anterior or dorsal is erected as the fish turns. It is often attracted by and watches closely anyone looking into its tank. The overall colour is a fine steely-blue with a velvety plum-like bloom, lighter on the underparts. The caudal fin is bordered by a dark band, with a tendency to a light outer edge. The iris is golden and black and the tip of the protuberant lower jaw has a dark patch. Altogether it is a strikingly handsome fish.

\section{REFERENCES}

BAteson, W., I890. The sense-organs and perceptions of fishes; with remarks on the supply of bait. Fourn. Mar. Biol. Assoc., Vol. I, pp. 225-56.

CLARK, R. S., I920. The pelagic young and early bottom stages of teleosteans. fourn. Mar. Biol. Assoc., Vol. 12, pp. 159-240.

Couch, J., I862. A History of the Fishes of the British Islands, Vol. I. London.

DAY, F., 1880-84. The Fishes of Great Britain and Ireland. London.

FAGE, L., 1918. Shore-Fishes. Rep. Danish Oceano. Expedit., 1908-10, to the Mediterranean and Adjacent Seas. No. 4, Vol. 2, A.3, pp. I-I54.

Holt, E. W. L., I89I. Survey of fishing grounds, west coast of Ireland, I890. I. On the eggs and larvae of teleosteans. Sci. Trans. Roy. Dublin Soc., Vol. 4 (Series II), pp. 435-74.

Roule, L., 1935. Fishes their ways of life. [Translated from the French by C. Elphinstone] London.

Steven, G. A., I947. The British Raiidae. Science Progress, Vol. 35, pp. 220-36.

WIIson, D. P., I949. Notes from the Plymouth aquarium. Fourn. Mar. Biol. Assoc., Vol. 28, pp. 345-5I. 